This is the author's final, peer-reviewed manuscript as accepted for publication. The publisher-formatted version may be available through the publisher's web site or your institution's library.

\title{
Girls' physical activity levels during organized sports in Australia
}

Justin M. Guagliano, Richard R. Rosenkranz, and Gregory S. Kolt

\section{How to cite this manuscript}

If you make reference to this version of the manuscript, use the following information:

Guagliano, J. M., Rosenkranz, R. R., \& Kolt, G. S. (2013). Girls' physical activity levels during organized sports in Australia. Retrieved from http://krex.ksu.edu

\section{Published Version Information}

Citation: Guagliano, J. M., Rosenkranz, R. R., \& Kolt, G. S. (2013). Girls' physical activity levels during organized sports in Australia. Medicine \& Science in Sports \& Exercise, 45(1), 116-122.

Copyright: ( 2013 The American College of Sports Medicine

Digital Object Identifier (DOI): doi:10.1249/MSS.0b013e31826a0a73

Publisher's Link: http://journals.Iww.com/acsmmsse/Abstract/2013/01000/Girls_Physical_Activity_Levels_during_Organized.17.aspx 


\title{
Girls’ physical activity levels during organized sports in Australia
}

\author{
Justin M. Guagliano ${ }^{1}$, Richard R. Rosenkranz ${ }^{1,2}$, and Gregory S. Kolt ${ }^{1}$
}

${ }^{1}$ School of Science and Health, University of Western Sydney, Sydney, Australia; and

${ }^{2}$ Department of Human Nutrition, Kansas State University, Manhattan, Kansas, U.S.A.

Corresponding Author: Richard R. Rosenkranz, PhD, Department of Human Nutrition, 201 Justin Hall, Kansas State University, Manhattan, KS 66506 USA. Telephone: 785.532.0152, Facsimile 785.532.3132. Email: ricardo@ksu.edu

Running Title: Activity levels during organized sports

Funding: This study was supported by the School of Science and Health at the University of Western Sydney.

Conflict of interest: Justin Guagliano has no potential conflict of interest to declare. Richard Rosenkranz has no potential conflict of interest to declare. Gregory Kolt has no potential conflict of interest to declare. 


\begin{abstract}
Purpose: The primary aim of this study was to objectively examine physical activity (PA) levels of girls during organized sport (OS), and to compare the levels between games and practices for the same participants. Secondary aims of this study were to document lesson context and coach behavior during practices and games. Methods: Participants were 94 girls recruited from 10 teams in three OS (netball, basketball, soccer) from the Western Suburbs of Sydney. Each participant wore an ActiGraph GT3X monitor for the duration of one practice and one game. The SOFIT was concurrently used to document lesson context and coach behavior. Results: Girls spent a significantly higher percentage of time in moderate-to-vigorous PA (MVPA) during practices compared to games $(33.8 \%$ vs. $30.6 \% ; t=2.94, P<0.05)$. Girls spent about $20 \mathrm{~min} / \mathrm{hr}$ in MVPA during practices and about $18 \mathrm{~min} / \mathrm{hr}$ in MVPA during games. An average of 2,957 and 2,702 steps/hr were accumulated during practice and games, respectively. However, girls spent roughly two-thirds of their OS time in light PA or sedentary. Based on SOFIT findings, coaches spent a large proportion of practice time in management $(15.0 \%)$ and knowledge delivery (18.5\%). An average of 13.0 and 15.8 occurrences/hr were observed during games and practices where coaches promoted PA. Conclusion: For every hour of game play or practice time, girls accumulated approximately one-third of the recommended 60 minutes of MVPA time and about one-quarter of the 12,000 steps that girls are recommended to accumulate daily. For this population, OS appears to make a substantial contribution to recommended amounts of MVPA and steps for participating girls. OS alone, however, does not provide amounts of PA sufficient to meet daily recommendations for adolescent girls.
\end{abstract}

Key Words: Children, Adolescents, Youth sports, MVPA, Accelerometer, SOFIT 


\section{Introduction}

Paragraph Number 1 The benefits of regularly engaging in moderate-to-vigorous physical activity (MVPA) among children and adolescents are well established, and include contributions to physical, mental, and social health outcomes (21). Public health guidelines state that children and adolescents should engage in 60 minutes of MVPA daily, which can be achieved cumulatively throughout the day in bouts (21). A considerable proportion of children and adolescents, however, fail to meet recommended levels of physical activity $(5,12,22,25)$. This is particularly evident for girls; they are less physically active than boys $(5,22)$, with the sharpest declines observed in adolescence $(7,12)$.

Paragraph Number 2 Participation in organized sports (OS) has been recommended as an approach to increase physical activity (27). In Australia, yearly prevalence data indicates that approximately $69 \%$ of children (67\% of girls) participate in at least one OS (including dance) outside of school hours (1). A recent systematic review found that children who participated in OS were more physically active than those who did not participate (13). However, the amount of physical activity that girls achieve during OS is unclear.

Paragraph Number 3 Of the few studies that have examined physical activity in OS, one study found that during soccer games, children were in MVPA for 33\% of the match (18) and another study found that about $46 \%$ of practice time was spent in MVPA (9). However, children also spend high percentages of time during OS inactive or in light physical activity $(6,9)$.

Despite these findings that children may be less than optimally active during OS practices and games, OS contributed close to $25 \%$ of daily MVPA $(18,28)$. These studies provide evidence to suggest that OS can contribute substantially to MVPA levels; however, current literature has only examined physical activity in either OS practices or games. To date, a complete picture of 
OS is lacking, where physical activity has been examined in both practices and games for the same participants to provide comparisons between conditions. Furthermore, it remains unclear with respect to opportunity for physical activity how time is spent and how coaches conduct themselves during practices and games in OS.

Paragraph Number 4 The primary aim of this study was to objectively examine physical activity levels of girls during OS, and to compare the levels between games and practices for the same participants. Secondary aims of this study were to document lesson context and coach behavior during practices and games.

\section{Methods}

\section{Participants}

Paragraph Number 5 A total of 94 girls between 11 and 17 years of age (mean age = $13.4 \pm 2.2$ years) participated in this study. Participants were recruited from OS clubs playing netball, basketball, and outdoor soccer in the Western Suburbs of Sydney, Australia. These three OS were chosen because of their popularity amongst girls in Australia (1). A convenience sample of ten teams from the three sports was recruited (four netball, three basketball, and three soccer). Initially, a member of the OS clubs executive committee was contacted by the primary investigator (JMG), to provide information about the study protocol. Interested clubs then provided the primary investigator with contact details of interested coaches. Detailed study information was then sent to coaches and parents. Participants were included based on their willingness to participate in the study. Prior to study commencement, informed consent and assent was obtained from coaches, parents, and athletes. The Human Research Ethics Committee of the University of Western Sydney approved this study.

\section{Protocol}


Paragraph Number 6 Between May and August 2011, a team consisting of the primary investigator (JMG) and a female research assistant attended practices and games of all participating teams. The team observed one practice and one game, with the exception of netball. The netballers practiced twice a week, with one of those practices dedicated solely to fitness. Therefore, an additional practice was observed (one fitness session and one skill session) for this sport. There was an average of 13 and 15 days between observed practices and games for netball and soccer, respectively, and an average of 11 days between observed practices, games, and fitness sessions for netball, respectively._Before the practice, participating girls were taken to a semi-private measurement area to be assessed on height, weight, and waist circumference. After anthropometric measurements, girls were fitted with an accelerometer that was placed on the right hip (described below), and worn for the duration of the practice. The majority of girls on each team wore accelerometers across sports (netball: 38/39, basketball: 28/30, and soccer 28/43). In addition to accelerometry, the System for Observing Fitness Instruction Time (SOFIT) (11) direct observation system was used by the primary investigator (described below). The protocol for games was the same as practice protocols, except that anthropometric measures were not taken.

\section{Anthropometric measures}

Paragraph Number 7 Prior to measurement, girls were asked to remove shoes and heavy clothing. Standing height was measured to the nearest $0.1 \mathrm{~cm}$ using a portable stadiometer (PE87 portable stadiometer; Mentone Educational, Victoria, Australia). Weight was measured using a digital scale (EF 538 HealthStream digital scale; Aussie Fitness, Queensland, Australia) to the nearest $0.1 \mathrm{~kg}$. Body mass index (BMI) was calculated and converted into age- and sex-specific percentiles using the Centers for Disease Control and Prevention growth charts (8). Waist 
circumference was measured on the right side of the body by finding the midpoint between the lowest rib and the iliac crest. A non-elastic tape measure (Myotape; Mentone Educational, Victoria, Australia) was wrapped snugly around the waist and measurement was taken at the end of exhalation to the nearest $0.1 \mathrm{~cm}$. Measurements were conducted in duplicate for all assessments, and an average was recorded. A third measurement was taken if the first two measures differed by more than $0.5 \mathrm{~cm}$ or $0.5 \mathrm{~kg}$, and the average was recorded. All anthropometric measures were used for descriptive purposes.

\section{Accelerometry}

Paragraph Number 8 The ActiGraph GT3X accelerometer (ActiGraph; Pensacola, FL) was used to assess physical activity levels in this study. ActiGraph accelerometers are the most widely used accelerometers, and have been shown to be valid and reliable devices for physical activity measurement in children and adolescents $(16,23)$. Accelerometers were initialized to record counts and steps with $5 \mathrm{~s}$ epochs specified, to capture effectively the intermittent activity patterns of children and adolescents (24).

Paragraph Number 9 Accelerometers were synchronized with an external clock and initialized to start recording a minimum of 30 minutes before and after the scheduled practice and/or game time. Start and finish times were recorded for every practice and game via direct observation to trim excess data outside the recorded start and finish time. Participating coaches and athletes were instructed by the research team not to change activities or the way they practiced or played games during observation.

Paragraph Number 10 After each practice or game, raw accelerometer counts were uploaded to a computer using ActiGraph software, and saved to a Microsoft Excel file. Data outside the recorded start and finish time for given sessions were disregarded. Data were checked 
for spurious values that did not coincide with the direct observation records; all data between start and finish times for all practices and games were included in the analyses. Freedson's MET prediction equation was used to determine physical activity intensity (4). The age-specific counts per minute were divided by 12 to account for our $5 \mathrm{~s}$ epochs. Physical activity intensity was classified as the following: sedentary (SED) $\leq 100$ counts/min; light physical activity (LPA) $\geq 1.5$ METs $<4$; moderate physical activity (MPA) $\geq 4$ METs $<7$; and vigorous physical activity (VPA) $\geq 7$ METs. Although a strong consensus does not exist regarding appropriate selection of MET intensity thresholds for children and adolescents (23), those selected for this study have been used in an adolescent female population (15).

\section{Direct observation}

Paragraph Number 11 To complement accelerometry, SOFIT was used in this study to provide contextual data on physical activity in OS. SOFIT is a widely used direct observation system that uses momentary time sampling to generate data on participant physical activity, lesson context, and instructor (or for our purposes, coach) behavior (11). SOFIT has demonstrated acceptable reliability and validity in a pediatric population $(11,17)$. Typically, SOFIT is used for structured PA sessions such as physical education classes, and OS provides a similar environment, led by a coach instead of a teacher. Although SOFIT can be easily implemented in an OS setting, only one report that we are aware of has used the direct observation system in OS (14).

Paragraph Number 12 With SOFIT, four (plus one alternate) participants are quasirandomly and furtively selected prior to session commencement by dividing the total number of participants attending a given session by five to inform selection order (e.g., 15/5 = 3, so every

$3^{\text {rd }}$ participant is selected). On a rotational basis, the physical activity levels, lesson context, and 
coach behavior were coded and recorded on paper every $20 \mathrm{~s}$ via a looped voice recording that prompted the observer to observe and record. However, physical activity data from SOFIT was not used in this study, due to the availability of accelerometer data that render physical activity data at the individual level.

Paragraph Number 13 The OS lesson context was coded into only one of six categories: management, knowledge delivery, fitness, skill practice, game play, and free play at the end of each 10 s observe interval. Coach behavior was coded using a hierarchical format and included (in hierarchal order) promotes physical activity (includes prompts of encouragement and praise) or discourages physical activity (includes prompts that are sarcastic and punitive in nature), demonstrates physical activity, and other. Therefore, promotes physical activity or discourages physical activity was recorded if it occurred at any time during the $10 \mathrm{~s}$ observe interval; whereas other was only scored if the other categories were not observed during the $10 \mathrm{~s}$ observe interval. Multiple coding was only permitted if promotes physical activity or discourages physical activity and demonstrates physical activity were observed at any time during the $10 \mathrm{~s}$ observe interval. SOFIT was used at each practice and game. The primary investigator (JMG) was fully trained to use the observation technique and conducted all direct observations.

Paragraph Number 14 The implementation of SOFIT is important to this study. SOFIT has not been used in these particular sports, therefore important information regarding lesson context and coach behavior is unknown. In other words, how time is spent and how coaches conduct themselves with regard to PA during practices and games in OS is unknown (13). Generating data on lesson context and coach behavior is best achieved through direct observation, as self-report data may be unreliable or otherwise biased (11).

\section{Statistical analysis}


Paragraph Number 15 All statistical analyses were performed with SPSS 18.0 (Chicago, IL, USA). Mean differences between practices and games for each physical activity intensity (SED, LPA, MPA, VPA, and MVPA), steps/hr, lesson context variables, and coach behavior variables were analyzed using paired samples $t$-tests. Analysis of variance (ANOVA) was used to examine the differences in means for the anthropometric measures collected for girls in each OS. Descriptive statistics included means and standard deviations. Statistical significance was set at $P<0.05$.

\section{Results}

\section{Participant characteristics}

Paragraph Number 16 Table 1 displays physical characteristics of participants by sport. Physical characteristics were assessed for $98.9 \%$ of participants (93/94 participants), as one participant was missing due to absence. The mean $( \pm \mathrm{SD})$ age of the participants was $13.4 \pm 2.2$ years. Based on age- and sex-specific growth charts, the average height $(164.1 \pm 8.1 \mathrm{~cm})$, weight $(56.9 \pm 10.9 \mathrm{~kg})$, and BMI $\left(21.0 \pm 3.2 \mathrm{~kg}^{-2}\right)$ for all participating athletes corresponded approximately to the $75^{\text {th }}$ percentile (8). Significant mean differences were found among sports for age, weight, and BMI $(P<0.05)$.

--Insert Table 1 near here--

\section{Physical activity intensity during practice and games}

Paragraph Number 17 Table 2 displays physical activity intensity (percent time) and step counts (per hr) at practice and games for each OS. Participants with intact data (attended both the observed practice and game) were 82 out of 94 participants $(87.2 \%)$. Mean $( \pm \mathrm{SD})$ duration, across OS, for practice was $82.6 \pm 22.6 \mathrm{~min}$ and $90.8 \pm 13.7 \mathrm{~min}$ for games. Across OS, the overall mean for percent time in MVPA during practices was significantly higher $(t=2.94, P$ 
$<0.05)$ than during games. Significant mean differences for percent time were found for each physical activity intensity across OS. During practices, the mean for percent time for VPA, MPA, and LPA were found to be significantly higher than during games (VPA: $t=2.67 ; P<$ 0.05 ; MPA: $t=2.14, P<0.05$; LPA: $t=5.18, P<0.001)$. The mean percent time for SED was significantly lower $(t=-5.20, P<0.001)$ during practice than during games.

Paragraph Number 18 The percentage of time spent in MVPA during games was slightly more homogenous than during practice. The only significant mean difference for percent time in MVPA between practice and games was found in basketball $(t=-2.34, P<0.05)$. With regard to LPA and SED, across all OS, participants spent a greater percentage of time in LPA ( $t$ $=6.71, P<0.001)$ and a lower percentage of time $\operatorname{SED}(t=-4.82, P<0.001)$ in practice compared to games.

Paragraph Number 19 Out of the three OS observed, netball was the only sport that dedicated one whole practice solely to fitness. During fitness practices, the mean percentage of time spent in MVPA was significantly greater than regular (skill-based) netball practices ( $t=$ 10.10, $P<0.001)$ and games $(t=8.73, P<0.001)$. Also, LPA and SED were significantly lower at fitness practices compared to regular practices (LPA: $t=-7.68, P<0.001$; SED: $t=-2.89, P<$ 0.05 ) and to games (LPA: $t=-7.38, P<0.001$; SED: $t=-4.49 ; P<0.001$ ).

\section{Steps counts during practice and games}

Paragraph Number 20 Across OS, participants accumulated significantly more steps/hr during practice than during games $(t=2.15, P<0.05)$ (See Table 2). Among sports, netball fitness practices provided significantly more steps $/ \mathrm{hr}$ compared to regular netball practices $(t=$ $10.10, P<0.001)$ and games $(t=9.50, P<0.001)$. 


\section{OS contribution to recommended levels physical activity}

Paragraph Number 21 On average, OS contributed $18.4 \mathrm{~min} / \mathrm{hr}$ of MVPA during games (netball: $18.8 \mathrm{~min} / \mathrm{hr}$; basketball: $18.3 \mathrm{~min} / \mathrm{hr}$; soccer: $17.5 \mathrm{~min} / \mathrm{hr}$ ) and $20.3 \mathrm{~min} / \mathrm{hr}$ during practice (netball: $20.2 \mathrm{~min} / \mathrm{hr}$; basketball: $21.3 \mathrm{~min} / \mathrm{hr}$; soccer: $18.9 \mathrm{~min} / \mathrm{hr}$ ). Large proportions of time, however, were spent in SED, on average $23.3 \mathrm{~min} / \mathrm{hr}$ during games (netball: $20.9 \mathrm{~min} / \mathrm{hr}$; basketball: $29.3 \mathrm{~min} / \mathrm{hr}$; soccer: $19.3 \mathrm{~min} / \mathrm{hr}$ ) and $18.1 \mathrm{~min} / \mathrm{hr}$ during practice (netball: 19.0 $\mathrm{min} / \mathrm{hr}$; basketball: $19.6 \mathrm{~min} / \mathrm{hr}$; soccer: $14.1 \mathrm{~min} / \mathrm{hr}$ ). Fitness practices provided approximately $27 \mathrm{~min} / \mathrm{hr}$ of MVPA and $16.3 \mathrm{~min} / \mathrm{hr}$ SED.

Paragraph Number 22 Participants across sports accumulated $22.6 \%$ and $24.2 \%$ of the recommended 12,000 daily steps (26) in one hour of game play (netball: $21.5 \%$ daily steps; basketball: $20.0 \%$ daily steps; soccer: $28.4 \%$ daily steps) and practice time (netball: $22.6 \%$ daily steps; basketball: $22.9 \%$ daily steps; soccer: $29.0 \%$ daily steps), respectively. During netball fitness practices, approximately $34.3 \%$ of the recommended 12,000 steps/day were accumulated every hour.

\section{Lesson context}

Paragraph Number 23 A total of 20 sessions were observed: eight netball (four games and four practices), six basketball (three games and three practices), and six soccer sessions (three games and three practices). Four fitness practices were also observed, but were not included in the overall comparison across OS because they were exclusive to netball. Table 3 displays lesson context as the percentage of a session that was spent in each category.

Paragraph Number 24 Across OS, percentage of time spent in the SOFIT categories of management, knowledge delivery, and free play did not significantly differ between practice and games. Mean percentages for fitness and skill practice were significantly higher during practice 
compared to games (fitness: $t=2.92, P<0.05$; skill practice: $t=4.66, P<0.05$ ); and mean percentages for game play were significantly higher during games compared to practice $(t=6.99$, $P<0.001)$.

\section{Coach behavior}

Paragraph Number 25 Though there tended to be more occurrences per hour of both promotion and discouragement of physical activity during games compared to practice, means were not significantly different. There were significantly fewer occurrences per hour of coaches demonstrating physical activity during games than during practice $(t=-2.95, P<0.05)$. These trends were consistent for across OS.

--Insert Table 3 near here--

\section{Discussion}

Paragraph Number 26 To our knowledge, this is the first study to examine physical activity in Australian OS and to compare mean proportions of physical activity levels of girls during practice and games in OS using the same participants. As far as we are aware, it is also the first to provide additional insight on lesson context and coach behaviors during OS through the inclusion of SOFIT in the peer-reviewed literature.

Paragraph Number 27 Our observations of the three sports showed that girls achieved significantly higher levels of MVPA during practice compared to games; accumulating approximately $20 \mathrm{~min} / \mathrm{hr}(\sim 34 \%$ time $)$ in MVPA during practice and about $18 \mathrm{~min} / \mathrm{hr}(\sim 30 \%$ time) in MVPA during games. The girls also accumulated an average of 2,904 and 2,709 steps/hr during practice and games, respectively. Therefore, for every hour of game play or practice time, girls accumulated approximately one-third of the recommended 60 minutes of MVPA (21) and about one-quarter of the 12,000 steps girls are recommended to accumulate daily (26). For this 
population, OS appears to make a substantial contribution to the recommended levels of physical activity of participating girls.

Paragraph Number 28 Our findings are comparable to findings of earlier studies.

Sacheck et al. (18) found approximately $33 \%$ of soccer games were spent in MVPA, whereas

Leek et al. (9) examined physical activity levels during soccer and baseball/softball practices and found children spent $46 \%$ of the practice time in MVPA across sports. Consistent with the present findings, practices may provide more MVPA compared to games. A possible explanation for this difference may be that coaches are better able to dictate the intensity of a practice, compared to a game. Also, a larger proportion of the team can participate simultaneously, and in smaller groups, which can provide increased opportunities for players to participate at a higher physical activity intensity during practice, compared to a game.

Paragraph Number 29 A study by Wickel and Eisenmann (28) sought to determine the contribution of $\mathrm{OS}$ (mean duration in $\mathrm{OS}=65 \mathrm{~min}$ ) to daily physical activity. Similar to our findings, OS contributed substantially to the amount of recommended MVPA on days where children participated in OS (approximately $23 \%$ or 26 mins) (28). The authors, however, indicated that this additional physical activity was not maintained on days without OS. These findings indicate that even though OS alone does not provide amounts of physical activity sufficient to meet daily recommendations, it does provide an ideal opportunity to be physically active and to contribute to daily MVPA of participating children. Furthermore, evidence indicates that children who participate in OS are more active than those who do not, and are more likely to meet recommended physical activity guidelines $(13,20)$.

Paragraph Number 30 Although OS provides a substantial proportion of the recommended amounts of MVPA, there may be potential for improvement in the contribution 
that OS makes to daily MVPA. In our study, a considerable proportion of practice and game time was spent insufficiently active (SED or LPA). Significantly higher proportions of time were spent SED ( $\sim 39 \%$ vs. $\sim 30 \%$ time) during game time compared to practice and vice-versa for LPA ( $\sim 31 \%$ vs. $36 \%$ time). On average, girls were SED or in LPA about $42 \mathrm{mins} / \mathrm{hr}(\sim 70 \%$ time $)$ during games and about $40 \mathrm{mins} / \mathrm{hr}(\sim 67 \%$ time) during practice. This finding is consistent with other studies that have observed sizeable proportions of game or practice time spent SED or in LPA $(6,9,18,28)$. Thus, there are clearly opportunities to increase MVPA, particularly during practices, in OS.

Paragraph Number 31 With the inclusion of SOFIT in this study, not only does it provide the first glimpse of how time is spent (lesson context) and coach behavior during these OS, it may also assist in identifying opportunities to increase MVPA, particularly during practice. To our knowledge, there are no peer-reviewed studies reporting use of SOFIT in OS, and only one published report has used SOFIT in an OS setting, where rugby league and rugby union practices were observed (14). Rugby coaches spent similar percentages of practice time in fitness (9\% vs. $\sim 9 \%$ ) and game play ( 20\% vs. $\sim 23 \%)$ compared to present study findings across OS. However, coaches in the present study spent a considerably higher percentage of practice time in management (15\% vs. $11 \%)$ and knowledge delivery ( $19 \%$ vs. $12 \%)$ and considerably lower percentage of practice time in skill practice ( $\sim 35 \%$ vs. $44 \%$ ) compared to rugby coaches.

Paragraph Number 32 Rugby players in the earlier report (14) spent a considerably higher percentage of time in skill practice, compared to our participants. It is likely that physical activity levels are higher during skill practice therefore; it is probable rugby players had more opportunities to be physically active during practice. It is also likely that children would be relatively inactive while in management and knowledge delivery. This has recently been 
exhibited in a physical education setting; the authors found a significant negative correlation between MVPA and time spent in management and knowledge delivery (2). Therefore, decreasing the percentage of time coaches spend in management and knowledge delivery may be a strategy to consider in helping create an environment that provides the most opportunity for physical activity.

Paragraph Number 33 Lastly, our findings indicate that coaches tended to promote physical activity (includes prompts of encouragement and praise) more frequently than they tended to discourage physical activity (includes prompts that are sarcastic and punitive in nature) during both games and practice. Coaches demonstrated physical activity more often during practice than during games. While one report (14) has used SOFIT in OS, direct comparisons of coach behavior could not be made due to differences in coding made by the authors for this phase of SOFIT. However, comparisons for promoting physical activity can be made with physical education teachers. Compared to physical education teachers, higher rates of promoting physical activity were found with coaches in the present study, which may lead to increased physical activity $(3,10,19)$.

Paragraph Number 34 A few potential limitations should be considered when interpreting the current findings. The present study was not designed for comparison between sports, but rather to describe physical activity levels of these three OS, and to compare physical activity levels during games and practices. Secondly, a convenience sample was used; therefore there is the potential for selection bias. Thirdly, physical activity findings were based on a single observation period for each team, that is, one game, one practice, and one fitness practice (for netball). Lastly, participants were recruited from only one club for each sport, and thus our ability to generalize the current findings may be limited. Despite these limitations, the present 
study used objective measures that allow for a rigorous description of the physical activity levels that girls achieved during practice and games in OS with some of the highest participation rates in Australia.

Paragraph Number 35 In conclusion, both games and practices in OS appear to have made a substantial contribution to the accumulation of recommended amounts of daily MVPA and steps of participating girls. However, OS alone did not provide a sufficient amount of physical activity to meet daily recommendations for adolescent girls. Across OS, large proportions of time were spent in SED or LPA. Also, considerable percentages of time were spent in management and knowledge delivery. Therefore, there is room for improvement with regards to optimizing physical activity levels in OS, particularly during practice, without compromising fundamental lessons and skills taught by coaches. This information on OS can be used as a platform on which to inform policies, and to develop strategies to increase adolescent girls' physical activity levels through OS. Because physical activity levels were not monitored on non-OS days in the current study, future research should examine the contribution OS has on physical activity levels during days of OS, compared to non-OS days for these sports.

Furthermore, support should be provided to coaches in an effort to increase MVPA and decrease SED time in OS, without interfering with fundamental learning opportunities and skill development that occur in OS.

Acknowledgements: This study was supported by the School of Science and Health at the University of Western Sydney. The authors wish to thank participating organizations and our research assistant. We also thank Dr. Chris Lonsdale for his constructive criticism of the manuscript. 
Conflict of interest: The authors have no conflict of interest to declare. The results of the present study do not constitute endorsement by ACSM. 


\section{References}

1. Australian Bureau of Statistics. Children's participation in organised sport and dancing. Available at http://www.abs.gov.au/ausstats/abs@.nsf/Products /4177.0 200910 Main+Features Characteristics+of+participation?OpenDocument. Accessed January 16, 2012.

2. Dudley DA, Okely AD, Cotton WG, Pearson P, and Caputi P. Physical activity levels and movement skill instruction in secondary school physical education. J Sci Med Sport. 2011. http://dx.doi.org/10.1016/j.jsams.2011.10.005

3. Fairclough S, and Stratton G. Improving health-enhancing physical activity in girls' physical education. Health Ed. Research. 2005;20(4):448-457.

4. Freedson P, Pober D, and Janz KF. Calibration of accelerometer output for children. Med. Sci. Sports Exerc. 2005;37(11):S523-S530.

5. Hardy LL, Okely AD, Dobbins TA, and Booth ML. Physical activity among adolescents in New South Wales (Australia): 1997 and 2004. Med. Sci. Sports Exerc. 2008;40(5):835-841.

6. Katzmarzyk P, Walker P, and Malina R. A time-motion study of organized youth sports. $J$ Human Mov. Studies. 2001;40(5):325-334.

7. Kimm SYS, Glynn NW, Kriska AM, Barton BA, Kronsberg SS, Daniels SR, Crawford PB, Sabry ZI, and Liu K. Decline in physical activity in black girls and white girls during adolescence. New Engl J Med. 2002;347(10):709-715.

8. Kuczmarski RJ, Ogden CL, Grummer-Strawn LM, Flegal KM, Guo SS, Wei R, Mei Z, Curtin LR, Roche AF, and Johnson CL. CDC growth charts: United States. Advance data. 2000;(314):1. 
9. Leek D, Carlson JA, Cain KL, Henrichon S, Rosenberg D, Patrick K, and Sallis JF. Physical activity during youth sports practices. Arch Pediatr Adol Med. 2011;165(4):294-300.

10. McKenzie TL, Catellier DJ, Conway T, Lytle LA, Grieser M, Webber LA, Pratt CA, and Elder JP. Girls' activity levels and lesson contexts in middle school PE: TAAG baseline. Med. Sci. Sports Exerc. 2006;38(7):1229-35.

11. McKenzie TL, Sallis JF, and Nader PR. SOFIT: system for observing fitness instruction time. J Teach Phys Educ. 1991;11(2):195-205.

12. Nader PR, Bradley RH, Houts RM, McRitchie SL, and O'Brien M. Moderate-to-vigorous physical activity from ages 9 to 15 years. JAMA: J Am Med Assoc. 2008;300(3):295-305.

13. Nelson TF, Stovitz SD, Thomas M, LaVoi NM, Bauer KW, and Neumark-Sztainer D. Do Youth Sports Prevent Pediatric Obesity? A Systematic Review and Commentary. Cur Sport Med Rep. 2011;10(6):360-70.

14. O' Connor D, Cotton W. Community Junior Sports Coaching. Available at http://www.dsr.nsw.gov.au/assets/pubs/industry/community_junior_sport_coaching_report.p df. Accessed February 23, 2012.

15. Okely A, Cotton W, Lubans D, Morgan P, Puglisi L, Miller J, Wright J, Batterham M, Peralta L, and Perry J. A school-based intervention to promote physical activity among adolescent girls: Rationale, design, and baseline data from the Girls in Sport group randomised controlled trial. BMC Pub Health. 2011;11(1):658.

16. Plasqui G, and Westerterp KR. Physical Activity Assessment With Accelerometers: An Evaluation Against Doubly Labeled Water. Obesity. 2007;15(10):2371-9. 
17. Rowe P, Schuldheisz J, and Van der Mars H. Measuring physical activity in physical education: validation of the SOFIT direct observation instrument for use with first to eighth grade students. Pediatr. Exerc. Sci. 1997;9(2):136-49.

18. Sacheck J, Nelson T, Ficker L, Kafka T, Kuder J, and Economos C. Physical activity during soccer and its contribution to physical activity recommendations in normal weight and overweight children. Pediatr. Exerc. Sci. 2011;23(2):281-92.

19. Sallis JF, McKenzie TL, Alcaraz JE, Kolody B, Faucette N, and Hovell MF. The effects of a 2-year physical education program (SPARK) on physical activity and fitness in elementary school students. Sports, Play and Active Recreation for Kids. Am. J Pub. Health. 1997;87(8):1328-34.

20. Silva P, Sousa M, Aires L, Seabra A, Ribeiro J, Welk G, and Mota J. Physical activity patterns in Portuguese adolescents: The contribution of extracurricular sports. Eur. Phys. Ed. Rev. 2010;16(2):171-81.

21. Strong WB, Malina RM, Blimkie CJR, Daniels SR, Dishman RK, Gutin B, Hergenroeder AC, Must A, Nixon PA, and Pivarnik JM. Evidence based physical activity for school-age youth. J Pediatrics. 2005;146(6):732-7.

22. Troiano RP, Berrigan D, Dodd KW, Mâsse LC, Tilert T, and McDowell M. Physical activity in the United States measured by accelerometer. Med. Sci. Sports Exerc. 2008;40(1):181-8.

23. Trost SG, Loprinzi PD, Moore R, and Pfeiffer KA. Comparison of Accelerometer Cut Points for Predicting Activity Intensity in Youth. Med. Sci. Sports Exerc. 2011;43(7):1360-8.

24. Trost SG, McIver KL, and Pate RR. Conducting accelerometer-based activity assessments in field-based research. Med. Sci. Sports \& Exerc. 2005; 37(11):S531S-543. 
25. Trost SG, Pate RR, Sallis JF, Freedson PS, Taylor WC, Dowda M, and Sirard J. Age and gender differences in objectively measured physical activity in youth. Med. Sci. Sports Exerc. $2002 ; 34(2): 350-5$.

26. Tudor-Locke C, Craig CL, Beets MW, Belton S, Cardon GM, Duncan S, Hatano Y, Lubans DR, Olds TS, and Raustorp A. How many steps/day are enough? For children and adolescents. Int. J Behav. Nutr Phys. Act. 2011;8(1):78.

27. Washington R, Bernhardt D, Gomez J, Johnson M, Martin T, Rowland T, Small E, LeBlanc C, Krein C, and Malina R. Organized sports for children and preadolescents. Pediatrics. 2001;107(6):1459-62.

28. Wickel EE, and Eisenmann JC. Contribution of youth sport to total daily physical activity among 6-to 12-yr-old boys. Med. Sci. Sports Exerc. 2007;39(9):1493-1500. 
Activity levels during organized sports 22

Table 1. Physical characteristics of the athletes by sport.

\begin{tabular}{ccccc}
\hline Girls & $\begin{array}{c}\text { All Sports } \\
(\mathbf{n = 9 3 )}\end{array}$ & $\begin{array}{c}\text { Netball } \\
(\mathbf{n = 3 7 )}\end{array}$ & $\begin{array}{c}\text { Basketball } \\
(\mathbf{n = 2 8})\end{array}$ & $\begin{array}{c}\text { Soccer } \\
(\mathbf{n = 2 8})\end{array}$ \\
\hline Age (yr) & $13.4 \pm 2.2^{*}$ & $13.2 \pm 1.1$ & $12.8 \pm 1.5$ & $14.3 \pm 3.3$ \\
Height (cm) & $164.1 \pm 8.1$ & $165.8 \pm 7.3$ & $162.3 \pm 10.3$ & $163.5 \pm 6.3$ \\
Weight (kg) & $56.9 \pm 10.9^{*}$ & $56.8 \pm 9.4$ & $53.2 \pm 12.3$ & $60.9 \pm 10.4$ \\
Waist circumference (cm) & $71.0 \pm 7.2$ & $71.1 \pm 5.6$ & $68.8 \pm 7.9$ & $72.9 \pm 8.0$ \\
BMI (kg.m-2) & $21.0 \pm 3.2^{*}$ & $20.6 \pm 2.8$ & $19.9 \pm 2.7$ & $22.8 \pm 3.7$ \\
BMI z-score & $0.4 \pm 0.8$ & $0.4 \pm 0.7$ & $0.3 \pm 0.8$ & $0.5 \pm 0.8$ \\
\hline
\end{tabular}

Values are mean \pm standard deviation

$\mathrm{n}=$ number of participants

* Significant mean difference by sport $(P<0.05)$ 
Table 2. Physical activity intensity (percent time) and step counts (per hr) at practice and games

\begin{tabular}{|c|c|c|c|c|c|c|c|c|c|}
\hline & \multicolumn{2}{|c|}{ All Sports $(n=82)$} & \multicolumn{3}{|c|}{ Netball $(n=36)$} & \multicolumn{2}{|c|}{ Basketball $(\mathbf{n}=27)$} & \multicolumn{2}{|c|}{ Soccer $(n=19)$} \\
\hline & Game & Practice & Game & Practice & Fitness & Game & Practice & Game & Practice \\
\hline MVPA & $30.6 \pm 9.5$ & $33.8 \pm 7.7^{*}$ & $31.4 \pm 9.0$ & $33.7 \pm 5.3 \bullet$ & $45.0 \pm 6.3 \cdot$ & $30.5 \pm 8.0$ & $35.5 \pm 8.1^{*}$ & $29.2 \pm 12.4$ & $31.5 \pm 10.5$ \\
\hline VPA & $14.9 \pm 6.5$ & $16.7 \pm 6.4^{*}$ & $15.5 \pm 5.9$ & $18.2 \pm 4.4^{*} \bullet$ & $29.4 \pm 6.6=$ & $17.7 \pm 5.0$ & $19.1 \pm 6.0$ & $9.6 \pm 6.6$ & $10.4 \pm 6.2$ \\
\hline MPA & $15.7 \pm 5.7$ & $17.1 \pm 5.0^{*}$ & $15.9 \pm 3.8$ & $15.4 \pm 2.8$ & $15.5 \pm 2.6$ & $12.8 \pm 4.2$ & $16.4 \pm 3.5^{*}$ & $19.6 \pm 7.9$ & $21.1 \pm 7.6$ \\
\hline LPA & $30.5 \pm 9.7$ & $36.0 \pm 8.4^{*}$ & $33.7 \pm 4.7$ & $34.7 \pm 4.8 \bullet$ & $27.8 \pm 4.6$ & $20.6 \pm 4.1$ & $31.6 \pm 6.7^{*}$ & $38.6 \pm 10.8$ & $45.0 \pm 9.3$ \\
\hline SED & $38.9 \pm 14.4$ & $30.1 \pm 10.6^{*}$ & $34.9 \pm 9.9$ & $31.6 \pm 7.2 \bullet$ & $27.1 \pm 5.9 \cdot$ & $48.9 \pm 11.3$ & $32.7 \pm 11.6^{*}$ & $32.2 \pm 18.3$ & $23.5 \pm 12.1^{*}$ \\
\hline Steps & $2,709 \pm 921$ & $2,904 \pm 728^{*}$ & $2,577 \pm 684$ & $2,716 \pm 385^{\bullet}$ & $4,110 \pm 746$ & $2,396 \pm 622$ & $2,753 \pm 767$ & $3,405 \pm 1,286$ & $3,475 \pm 894$ \\
\hline
\end{tabular}

Values are mean \pm standard deviation

$\mathrm{n}=$ number of participants; MVPA = moderate-to-vigorous physical activity; VPA = vigorous physical activity; MPA = moderate physical activity; LPA = light physical activity; SED = sedentary

* Significant difference between game and practice $(P<0.05)$

- Significant difference between netball practice and fitness $(P<0.05)$

- Significant difference between netball game and fitness $(P<0.05)$

Note: Fitness means not included in All Sports' means \pm standard deviations because they were exclusive to netball. 
Table 3. Lesson context and coach behavior during practice and games, based on direct observation by SOFIT

\begin{tabular}{|c|c|c|c|c|c|c|c|c|c|}
\hline & \multicolumn{2}{|c|}{ All Sports $(n=20)$} & \multicolumn{3}{|c|}{ Netball (n = 12) } & \multicolumn{2}{|c|}{ Basketball $(n=6)$} & \multicolumn{2}{|c|}{ Soccer $(n=6)$} \\
\hline & Game & Practice & Game & Practice & Fitness & Game & Practice & Game & Practice \\
\hline \multicolumn{10}{|l|}{ Lesson context (\%) } \\
\hline Management & $11.1 \pm 3.9$ & $15.0 \pm 4.7$ & $13.4 \pm 3.8$ & $14.3 \pm 1.7$ & $22.3 \pm 8.2$ & $9.5 \pm 4.6$ & $12.9 \pm 0.3$ & $9.5 \pm 2.7$ & $18.0 \pm 8.5$ \\
\hline Knowledge & $8.8 \pm 4.4$ & $18.5 \pm 13.7$ & $6.3 \pm 2.2$ & $25.0 \pm 15.0$ & $9.9 \pm 10.3$ & $15.9 \pm 1.9$ & $22.4 \pm 10.5$ & $5.1 \pm 3.3$ & $5.8 \pm 7.2$ \\
\hline Fitness & $2.3 \pm 2.4$ & $8.5 \pm 5.8^{*}$ & $4.4 \pm 2.1$ & $9.5 \pm 5.0^{\bullet}$ & $60.5 \pm 12.1$ • & $1.2 \pm 2.1$ & $2.6 \pm 2.7$ & $0.6 \pm 1.0$ & $13.1 \pm 4.6$ \\
\hline Skill practice & $6.9 \pm 4.6$ & $34.9 \pm 18.2 *$ & $10.1 \pm 3.2$ & $37.4 \pm 14.3^{*}$ & $5.3 \pm 10.6$ & $4.3 \pm 5.4$ & $50.9 \pm 13.8^{*}$ & $5.2 \pm 3.7$ & $15.5 \pm 5.7^{*}$ \\
\hline Game play & $69.4 \pm 9.0$ & $22.6 \pm 24.9^{*}$ & $61.9 \pm 3.2$ & $13.3 \pm 24.8^{*}$ & $0 \pm 0$ & $69.0 \pm 3.6$ & $10.6 \pm 13.6^{*}$ & $79.7 \pm 8.1$ & $47.2 \pm 19.6 *$ \\
\hline Free play & $1.6 \pm 4.6$ & $0.5 \pm 0.6$ & $3.9 \pm 7.1$ & $0.4 \pm 0.9$ & $1.9 \pm 2.7$ & $0 \pm 0$ & $0.5 \pm 0.3$ & $0 \pm 0$ & $0.4 \pm 0.6$ \\
\hline \multicolumn{10}{|l|}{$\begin{array}{l}\text { Coach behavior } \\
\text { (occurrence/hr) }\end{array}$} \\
\hline Promotes PA & $15.8 \pm 9.6$ & $13.0 \pm 11.5$ & $23.2 \pm 11.2$ & $21.7 \pm 8.2 \bullet$ & $7.8 \pm 5.6=$ & $13.3 \pm 1.4$ & $12.2 \pm 11.3$ & $8.3 \pm<0.1$ & $1.9 \pm 0.8$ \\
\hline Discourages PA & $1.9 \pm 2.9$ & $1.2 \pm 1.5$ & $2.3 \pm 2.0$ & $2.1 \pm 1.8$ & $0.4 \pm 0.5$ & $3.0 \pm 4.4$ & $1.2 \pm 1.0$ & $0.2 \pm 0.3$ & $0 \pm 0$ \\
\hline Demonstrate PA & $2.7 \pm 4.4$ & $7.6 \pm 6.1^{*}$ & $1.9 \pm 1.7$ & $3.8 \pm 1.0$ & $3.7 \pm 3.9$ & $3.0 \pm 4.4$ & $9.4 \pm 5.3$ & $3.6 \pm 6.4$ & $5.6 \pm 4.6$ \\
\hline
\end{tabular}

Values are mean \pm standard deviation

$\mathrm{n}=$ number of observations

$\mathrm{PA}=$ physical activity

* Significant difference between game and practice $(P<0.05)$

- Significant difference between netball practice and fitness $(P<0.05)$

- Significant difference between netball game and fitness $(P<0.05)$

Note: Fitness means not included in All Sports' means \pm standard deviations because they were exclusive to netball. 